\title{
Spiritual care in the training of hospice volunteers in Germany
}

\author{
MARGIT GRATZ, DIPL.THEOL., ${ }^{1,2}$ PIRET PAAL, PH.D., ${ }^{2}$ MORITZ EMMELMANN, M.ED., ${ }^{1}$ AND \\ TRAUGOTT ROSER, TH.D. ${ }^{1}$ \\ ${ }^{1}$ Department of Practical Theology, University of Muenster, Muenster, Germany \\ ${ }^{2}$ Department of Palliative Medicine, University Hospital of Munich, Germany \\ (RECEIVEd March 6, 2015; AcCEPTEd September 30, 2015)
}

\begin{abstract}
Objective: Hospice volunteers often encounter questions related to spirituality. It is unknown whether spiritual care receives a corresponding level of attention in their training. Our survey investigated the current practice of spiritual care training in Germany.

Method: An online survey sent to 1,332 hospice homecare services for adults in Germany was conducted during the summer of 2012. We employed the SPSS 21 software package for statistical evaluation.

Results: All training programs included self-reflection on personal spirituality as obligatory. The definitions of spirituality used in programs differ considerably. The task of defining training objectives is randomly delegated to a supervisor, a trainer, or to the governing organization. More than half the institutions work in conjunction with an external trainer. These external trainers frequently have professional backgrounds in pastoral care/theology and/or in hospice/ palliative care. While spiritual care receives great attention, the specific tasks it entails are rarely discussed. The response rate for our study was $25.0 \%(n=332)$.

Significance of results: A need exists to develop training concepts that outline distinct contents, methods, and objectives. A prospective curriculum would have to provide assistance in the development of training programs. Moreover, it would need to be adaptable to the various concepts of spiritual care employed by the respective institutions and their hospice volunteers.
\end{abstract}

KEYWORDS: Training program, Hospice volunteers, Palliative care, Spirituality, Spiritual care

\section{INTRODUCTION}

There are currently approximately 80,000 hospice volunteers in Germany (BMG, 2012), and that number is steadily increasing. These volunteers are likely to encounter a variety of questions pertaining to the spiritual in the hospice context depending on the particular environment and the amount of time they spend in the respective institution. The goal of our study was to investigate the assumption that the concept of a spiritual dimension in human life and the task of providing spiritual care are appropriate

Address correspondence and reprint requests to Margit Gratz, Department of Practical Theology, University of Muenster, Universitaetsstr. 13-17, 48143 Muenster, Germany. E-mail: margit. gratz@uni-muenster.de elements to be included in programs that train volunteers to do hospice work. The relevance of this subject is underscored by studies from the clinical context, which have found that the work of hospice and palliative care professionals profited greatly from training that addresses the topic of the spiritual (Wasner et al., 2005; Scherwitz et al., 2006). Given the regularity of the training programs, the increasing experience of volunteers with hospice work, and the growing challenges of multi-professional practice, these programs will need to face growing demands (Radbruch \& Payne, 2010), as well as the need for further development of their content (Wilson, 2000). This is particularly true for the most nebulous aspect of this subject matter: spirituality at the end of life. In the face of the existential threat inherent in 
the process of dying, hospice volunteers and all other professionals must be prepared to perceive this inner dimension of the dying patient, and to accommodate it appropriately (Gamondi et al., 2013). The indeterminate character of spirituality is an essential element of its description or definition (Roser, 2012), because spirituality is "precisely-and exclusivelythat which the patient deems to be spirituality" (Roser, 2011). The bounteous stock of hospice work duties that can be found in the pertinent literature could help to create training programs that teach an appropriate way of dealing with the fundamental obscurity of spirituality in this context.

This study was intended as an initial step in the development of a curriculum to be employed to prepare hospice volunteers in hospice homecare services to deal with spiritual care for inpatients. Its aim was not to produce a definition of spirituality at the end of life; rather, it sought to create a curricular guideline that would enable the providers of hospice care to train their staff in a way that would equip them to carry out spiritual care as deemed appropriate by the respective service provider. Such a curriculum would need to fulfill two seemingly conflicting tasks: it must present a sound foundation that provides orientation for training programs, and, at the same time, it needs to allow for the dynamics and individual adaptations implicit in patient-orientated spiritual care.

\section{OBJECTIVES}

Our study surveyed the current hospice care practices on the subject of spirituality in the context of training hospice volunteers to provide care in a German hospice. More specifically, we sought to illustrate what level of importance is generally given to this topic, what group of people is involved in the definition of course objectives, how the trainers are selected, and what the professional qualifications or backgrounds of these trainers are. It also hoped to gain an understanding of the relationship between elements of pastoral care and practical hospice work. The survey investigated what hospice care providers view as the spiritual care that can be provided by volunteers and how the volunteers are equipped to carry out these tasks. The data on volunteer training that we collected for the study are expected to also allow for insights into the training context generally.

\section{METHODS}

The quantitative survey invited the 1332 hospice homecare services in Germany to share their experiences and practices regarding training in matters of spirituality. Invitations were sent by letter, and the survey itself was conducted online between July and September of 2012. It consisted of items for single, multiple, and free-text responses as well as numerical rating scales ranging from 1 to 10 . A reminder was sent by letter in August of 2012, which resulted in our final returns.

The volunteer or full-time coordinators of the providers of hospice homecare were surveyed on, among other things, general information about their organization, spirituality and spiritual care in hospice homecare work, and their respective training programs for hospice volunteers.

The researchers developed a pretest version of the survey that was assessed in a trial run among six providers of hospice homecare. The research team at the Professorship of Spiritual Care at Munich University Hospital discussed the feedback and sent an improved version of the survey, including 49 items online, after revisions. The web portal employed for this survey was particularly user-friendly, for example, allowing one to skip back and forth through answers, to edit previously entered answers, and to pause participation in a survey until a more convenient time. The survey was conducted anonymously and evaluated using the SPSS 21 software package. Approval from an ethics committee was not required for this study.

\section{RESULTS}

The final return rate amounted to $25.0 \%(n=332)$. Nearly half of the providers of hospice care who participated in the survey $(44.3 \%, n=147)$ are located in the southern part of Germany. All the others are almost evenly distributed among the northern, western, and eastern parts. Participants had the following organizational structures:

nonprofit association $(53.9 \%, n=179)$

- church-based charity (either Catholic or Lutheran) $(20.5 \%, n=68)$

non-church-based charity $(1.2 \%, n=4)$

- organization with no formal ties to any other set structures $(6.3 \%, n=21)$

other type of organization $(7.5 \%, n=25)$

no answer $(10.5 \%, n=35)$

Two thirds of the hospice homecare services $(68.1 \%$, $n=226$ ) involved 40 hospice volunteers or less in 2011. A midlevel group of services with 40 to 70 volunteers included 27 services (8.1\%). Relatively few services $(8.7 \%, n=29)$ involved more than 70 
volunteers, and $17(n=5.1 \%)$ providers of hospice homecare did not provide an answer to this question.

The data regarding numbers of completed end-oflife care accompaniments in 2011 display a similar trend. More than half of the services $(53.9 \%, n=$ 179) provide care until death for 40 persons or less. The midlevel group is represented by $75(22.6 \%)$ of the responding services, who provide care for 40 to 70 persons. Some $60(18.1 \%)$ participants in the study stated that they provide care for more than 70 persons, and $18(5.4 \%)$ opted to not answer this item.

\section{Spirituality}

\section{Addressing Spirituality in the Training of Hospice Volunteers}

The study obtained four different responses regarding the formatting of the course of instruction provided for prospective hospice volunteers. Well over a quarter $(28.3 \%, n=94)$ of hospice care providers offer training regarding spirituality as an en-bloc course, on average comprising 5.25 hours of instruction (range $=2$ to 20 hours of instruction). A total of $98(29.5 \%)$ of service providers view spirituality as the basis for the entire training program, discussing it repeatedly and in a number of ways in their courses. Another 75 (19.6\%) occasionally incorporate spirituality into their training in the context of other topics. Four of the reporting services (1.2\%) entirely exclude spirituality from their courses.

\section{Trainers and Their Qualifications}

In the investigation of current practices of training in matters of spirituality, it is crucial to know who is assigned by governing bodies to instruct hospice volunteers regarding spiritual care:

- A statistical analysis of the multiple response items shows that more than a quarter $(28.9 \%$, $n=96$ ) cooperate exclusively with an external trainer. Only $45(13.6 \%)$ of those 96 providers of hospice care stated that they have a defined set of course objectives. The particular goals of the training provided by the remaining 10 $(3.0 \%)$ that reported not having such a set, as well as by the $41(12.4 \%)$ institutions that opted not to answer this item, remain unclear.

- The same is true of the $77(23.2 \%)$ services that provide training in matters of spirituality themselves but cooperate with an external trainer. These services apply a mixed format, involving both an external and an internal trainer (frequently the coordinator of hospice homecare services). Among them, only 48 (14.5\%) stated that they employ a description of specific course objectives. Regarding the remaining 15 (4.5\%) that do not have a definition of course objectives and the $14(4.2 \%)$ that did not respond to this item, the content on cooperation remains unclear.

Some $27.4 \%(n=91)$ of the services provide their training without assistance from external advisors.

- The remaining institutions $(20.5 \%, n=68)$ chose to not respond to this item.

In order to gain knowledge of trainers' professional qualifications, the survey allowed for multiple responses regarding their backgrounds in hospice/palliative care as well as in pastoral care/theology. Both backgrounds allowed differentiating between practical and theoretical qualifications. The responses show the following:

Some $12.7 \%(n=42)$ of trainers have professional knowledge and experience in pastoral care/theology exclusively. The data allow for the computation that $25(7.5 \%)$ of these are hired as external trainers. In $2(0.6 \%)$ of these 25 cases, the hospice services have a defined set of objectives for training but do not require their trainers to teach according to those objectives. A total of $8(2.4 \%)$ pass on their course objectives to the trainers, and the remaining 15 (4.5\%) of the 25 institutions hiring external trainers did not comment on how they proceed in such situations.

- Some $18.7 \%(n=62)$ of trainers have professional knowledge and experience in hospice/ palliative care exclusively.

A total of $45.8 \%(n=152)$ of trainers have professional knowledge and experience in both areas.

\section{Defining Course Aims}

Bearing in mind that it was not the purpose of our study to define what spirituality at the end of life is and how spiritual care must be conducted during this phase, a question arises: Who determines the goals that are to be pursued by the volunteer training programs in the context of each individual hospice homecare service? Different decision makers are involved in issuing course objectives (the item allowed for multiple responses):

supervisor $(63.6 \%, n=211)$

institution $(25.6 \%, n=85)$ 
trainer $(22.3 \%, n=74)$

undetermined $(0.9 \%, n=3)$

Where decisions about course objectives are made by the supervisor, this person is most frequently the service coordinator or at least comes from within the respective institution $(43.4 \%, n=144)$. Only 12 of the reporting services (3.6\%) delegate this decision entirely to an external supervisor. The remaining 55 (16.6\%) assigning the decision on course objectives to a supervisor did not answer the question as to whether the person providing the course was internal or external to the institution.

\section{Reflection of Course Participants on Their Own Spirituality}

Reflection on participants' personal spirituality may be a part of the training programs offered to hospice volunteers. Responses ranking the importance of this aspect of training showed an average of 8.3 (range $1-10, S D=1.9$ ) on a scale of 1 to 10 . Some $74.7 \%(n=248)$ of participants stated that they place such reflection in the curriculum of their courses.

\section{Working Definition of "Spirituality"}

Some $86.5 \%(n=45)$ of respondents answered affirmatively to the question of whether the course discussed the meaning of the term "spirituality." In light of the many significances for the meaning of "spirituality" that can be found in the pertinent literature, the courses work with a diverse set of definitions for the term:

- Some $28.0 \%(n=93)$ leave it to the trainer to choose the definition they work with.

- A total of $15.4 \%(n=51)$ rely on the working definition of the German Association for Palliative Care (DGP, 2007).

- Some $12.7 \%(n=42)$ are informed by the understanding of spirituality advocated by the organization that governs and funds their hospice homecare service; $28(8.4 \%)$ are church-based hospice services.

- Some 3.9\% $(n=13)$ rely on the definition provided by the European Association for Palliative Care (EAPC) (Nolan et al., 2011).

a total of $20.2 \%(n=67)$ state that they do not use any definition.

- Only $4.5 \%(n=15)$ refer to other sources (Buddhist tradition, encyclopedias, Viktor Frankl, and others).

\section{Spiritual Care}

Beyond a particular definition of "spirituality," spiritual care is essential to the hospice context, according to the responses from providers of hospice care surveyed in our study. They attributed a relatively high level of importance to spiritual care (7.6 on average, range $=2$ to $10, S D=1.9$ ), and deemed it equally important to instruct hospice volunteers in the specific tasks connected to spiritual care (7.7 on average, range $=1$ to $10, S D=2.2$ ). While $62.4 \%$ $(n=207)$ said that they speak about such tasks, nearly as many $(57.8 \%, n=192)$ stated that they do not define these tasks specifically in the training.

\section{Continued Training}

The participants assessed the need for continued training of hospice volunteers who have completed basic training and have entered active service to be a relevant issue ( 6.5 on average, range $=1$ to $10, S D=$ 2.2). However, only $46.7 \%(n=155)$ of participating institutions offer courses for continued training.

\section{Church-Based Organizations}

Some $28.9 \%$ ( $n=96$ ) of the surveyed providers of hospice care are run by a church-based organization. Among these, $21.4 \%(n=71)$ view it as important that hospice volunteers adopt the position of the denomination running the institution for which they volunteer. Another 6.9\% $(n=23)$ do not find it to be important, and the remaining 2 of 96 did not answer this item.

Nearly as many $(20.8 \%, n=69)$ of these 96 church-based organizations do not view it as problematic if the denominational background of the hospice service is not recognizable in the concrete work of the hospice care personnel. Another 7.5\% $(n=25)$ take the opposite position, stating that it is important to highlight the denominational background of the organization, and the remaining 2 participants did not respond to this item.

\section{Interconnection with Pastoral Care}

Well over half of the hospice care providers $(70.8 \%$, $n=235$ ) reported that their service is interconnected with pastoral care or that it upholds some form of contact with providers of pastoral care. Fixed partnerships between hospice care and pastoral care were found occasionally $(11.4 \%, n=38)$. About a fourth $(24.7 \%, n=82)$ of the institutions have access to providers of pastoral care who are actively involved in their institution. Only $12(3.6 \%)$ of the hospice homecare services stated that they have no connection to providers of pastoral care. This item was not answered by $102(30.7 \%)$ providers. 


\section{DISCUSSION}

\section{Spirituality}

\section{Addressing Spirituality in Training of Hospice Volunteers}

The research and professional literature have repeatedly demonstrated that spirituality is a relevant resource in cases of serious illness and that the spiritual needs and resources of the affected patients vary considerably (Büssing et al., 2009; Phelps, 2012; Alcorn et al., 2010). Spiritual care is a task assigned to all healthcare professionals (Hanson et al., 2008) providing end-of-life care and thus falls within the realm of the responsibilities of hospice volunteers (Höver \& Schaeffer, 2009; Hagen \& Raischl, 2011).

The subject of training of hospice volunteers in matters of spirituality therefore requires an appropriate amount of attention. The variety of formats within which spirituality is discussed in the present training programs (as a single unit of instruction or as the foundation of the entire course) illustrates that this is indeed the case among German providers of hospice homecare. Spirituality is recognized internationally as a relevant issue in the training of volunteers, but a lack of foundational research persists nonetheless. One of the few examples of a study that addresses spiritual care training for volunteers speaks to local congregations ("community members"), who perform part of their service within a hospice context in the United States (Raab, 2005). But the literature is sparse regarding the training of hospice volunteers specifically. Since training in matters of spiritual care is recognized as important not simply for volunteers but for all healthcare professionals, research concerning spirituality among occupational nurses and physicians is somewhat more extensive. Nurses generally regard the provision of spiritual care as one of their responsibilities, but they view themselves as inadequately trained for this task (McSherry \& Jamieson, 2011). Spirituality is an important aspect of the work of physicians in palliative care-both for themselves and their patients-and needs to be addressed in their professional training (Penderell \& Brazil, 2010). Very broadly speaking, the importance of the integration of hospice volunteers into palliative care teams and of the training of volunteers is recognized outside of Germany as well (Wilson, 2000; Scherwitz et al., 2006).

\section{Trainers and Their Qualifications}

About half of the providers of hospice homecare involve some external professional assistance in training their volunteers, and they consequently need to negotiate the contents of this training. Since the objectives of that training are not defined, it remains unclear how the content is negotiated with an external trainer.

It is safe to say that the quality of training is affected positively by the fact that roughly half of the trainers in matters of spirituality have expertise in pastoral care/theology or hospice/palliative care. Such field experience and dual areas of competence cannot necessarily be expected from theologians, pastoral care professionals, or hospice care employees and palliative care services alone.

For those having experience in pastoral care or theology only, the question arises as to how the contents that are essential to the tasks of hospice volunteers can be taught with a focus on spiritual care, avoiding a broader orientation toward pastoral care.

Regarding the institutions teaching their courses exclusively on the basis of hospice or palliative care and without a connection to pastoral care or theology, it remains unclear how they are able to ensure integration of pastoral care elements into volunteers' training.

Some research on the effects of training in spiritual care has already been published (Paal et al., 2015). One author offers the important caveat that training results have yet to be determined in situations where the trainers were not involved in developing the training program (Meredith, 2012). The research that is to follow the survey presented in this paper will therefore investigate the suitability of the planned spiritual care curriculum for application by trainers. Evaluation of a pilot course will provide information on the possible effects on training results.

The majority of research on spirituality in the health sector concerns itself with the effects of spirituality on a large array of professions, as well as with the gains in spiritual care competence that may be facilitated through training. Research that seeks to produce concrete descriptions of course objectives or trainers' tasks is ongoing. Future research on spiritual care would therefore have to consider questions regarding the working environment and the qualifications of trainers for training in spiritual care.

\section{Course Aims}

The results raise the question of what forms of involvement in hospice care are maintained by those supervisors and trainers who decide on the goals of volunteer training courses. Since most of those hospice care providers delegating the definition of course objectives to the supervisor are recruiting supervisors from their own staff, we can assume that a connection of the courses to hospice and palliative care is generally ensured. 
Among the quarter of services that opt to have the trainer decide on course objectives, four institutions employ trainers without any background in hospice and palliative care. This begs the question of how these trainers can know the task-specific, practical needs of hospice volunteers. In these cases, negotiation of concrete course objectives would be particularly important.

Concrete course goals require and include specification of tasks. The fact that course goals are so rarely described explicitly may therefore stem from the reported reluctance of hospice care providers to discuss spiritual care tasks of hospice volunteers in detail during training programs.

The importance of competency in spiritual care among hospice volunteers has been asserted frequently, but a lack of precise renderings of these competencies persists. Clarification of this issue requires further research. Publications concerning other healthcare professionals provide a sound foundation for future studies (Cooper et al., 2010; Marr, 2007), as they facilitate the framing and specification of the tasks of hospice volunteers. It must be kept in mind, however, that the construction of a concept for training volunteers cannot rely solely on descriptions of their expected tasks and other typical contents. It should be guided predominantly by the course objectives that flow from the specific tasks, challenges, and conversational topics they encounter during practical hospice work (Müller \& Heinemann, 2014; Planalp et al., 2011).

\section{Incorporating Self-Reflection}

The central role of patients' spirituality in the work of hospice care volunteers results in a prominent position of self-reflection by course participants regarding their own spirituality. A position stated in the free-text items that is shared by most providers of hospice care reads as follows: "Especially in the field of hospice homecare, it is very important to assist the seriously ill in the endeavor to live his or her spirituality until the end." In order to offer such assistance, hospice volunteers must have developed a well-reflected and solidified stance toward spirituality. "Overall, it is important to distinguish between the perception of someone else's spiritual dimension that ties in with one's own spiritual experience [...] and someone else's spiritual dimension that is foreign to one's own experience or even contradicts it. Praxis shows that voluntary visiting services only display this competence [to distinguish] if they participate in professional mentoring and training" (Hagen \& Raischl, 2011). An important side effect of the development of personal spirituality or religiosity is its benefit as a resource for coping with long-term ex- posure to death and the process of dying (Brown, 2011). Both self-reflection and self-care must receive attention in spiritual care (Penderell \& Brazil, 2010; Cooper et al., 2010; Owen-Still, 1985). All this illustrates that spirituality and spiritual care are indispensable thematic elements in training hospice volunteers.

\section{Working Definitions}

The available literature reflects the various open approaches to spirituality. Examples of frequently cited elements are the person-centered approach or a distinction between religious care and spiritual care (Gordon \& Mitchell, 2004; Puchalski et al., 2009; Pesut, 2003; Surbone \& Baider, 2010). While spirituality is discussed frequently and extensively in volunteer training programs, the definitions upon which this discussion is based come from a diverse set of sources. This observation does not allow us to conclude whether the governing organization, the supervisor, and the trainer coordinate their use of definitions and whether the providers of hospice care take distinctive stances toward spirituality. It also remains undetermined to what extent the providers utilize descriptions of spirituality-for example, the one developed by the Deutsche Gesellschaft für Palliativmedizin (DGP)_as working definitions, or take advantage of the ambiguity of the term (Roser, 2012). For hospice homecare services, it is more important to engage in a dialogue about how spirituality is to be treated, managed, and explained (or not explained) than to find a concrete definition of the term.

\section{Spiritual Care}

Spirituality as an existential dimension of human beings - the task of providing spiritual care is an entirely different thing. One of the most striking results of our study is the discrepancy between (1) the fact that hospice volunteers' tasks are addressed during the training program and (2) the responses indicating that training does not identify concrete tasks. It follows that spiritual care by volunteers is discussed without a detailed description of what spiritual care is and what competencies are required. The data do not reveal whether this is the case because the set of tasks is understood as self-evident or, conversely, because it is unclear or misunderstood. Spiritual care does not aim for attainment of specific objectives. If spirituality must be regarded as something profoundly subjective, then spiritual care can only hope to draw near to this internal aspect of another person.

Numerous authors have pointed out that spiritual needs at the end of life often receive insufficient 
attention or remain entirely unnoticed (Hermann, 2007; Epstein-Peterson et al., 2014; Hampton et al., 2007; Vallurupalli et al., 2012). This is aggravated by the fact that people communicate their spiritual needs in a variety of ways. The voicing of needs therefore requires various forms of support (Puchalski et al., 2009; Surbone \& Baider, 2010; Tan et al., 2005; Okon, 2005; Liu, 2014; Frick et al., 2005; Borneman et al., 2010). This support can be successful if training programs include instruction in spiritual care (Meredith, 2012; Marr et al., 2007; Owen-Still, 1985; Gordon \& Mitchell 2004; Epstein-Peterson, 2014; Yardley et al., 2009; Lillis, 2014; Wesley et al., 2004).

Only occasionally do publications elaborate on the specifics of the spiritual care provided by nurses and physicians. In contrast, a concrete description of the tasks of hospice volunteers would need to reflect on their particular role within hospice and palliative care services. These tasks in spiritual care are manifold and challenging, and the intended curriculum would address them specifically.

\section{Continued Training for Active/Experienced Volunteer Hospice Volunteers}

We can assume that an increased supply of continued training programs would be received well among hospice services. This assumption is based on the finding that continued training for active or experienced hospice volunteers is regarded as important while further training opportunities are relatively sparse. The survey does not indicate exactly why the demand for continued training is not being satisfied even in the face of a growing educational sector. It does, however, seem safe to assume that many institutions have to distribute a limited budget for continued training among many issues of similar urgencyfor example, as provision of assistance to persons suffering from dementia.

A U.S. study recently analyzed the demand for continued training for hospice volunteers and identified ethical questions, communication, and spirituality as three of the nine major issues in this area (Lavenburg \& Bernt, 2012).

\section{Connection to Church-Based Organizations}

More than half of the hospice homecare services participating in our study are nonprofit organizations and are not tied to or run by a church-based organization. Consequently, they have no formal obligation to communicate a particular approach to spirituality in their volunteer training. There are denominationally independent providers of hospice care who nonetheless make Christianity or another religious orientation the basis of their work. Their decision to do so usually follows from the historical tradition of hospice care and the conviction that Christian values correspond well to the fundamental interests and objectives of hospice work. The responses from the church-based hospice services underscore that advocacy of concrete religious ideas is not a common objective of encounters. Further, a large number of services do not expect their hospice volunteers to represent the denomination's background through a form of practical work with those who are receiving care. Nonetheless, the personal spiritual and religious backgrounds of hospice volunteers and the care team as well as the denominational orientation of the organization running the institution remain an important foundation for their work.

\section{Interconnections}

Our data indicate that almost all hospice homecare services maintain some form of interconnection or cooperation with local providers of pastoral care. The specific tasks fulfilled by these pastoral care partners and the frequency of their involvement were not surveyed in our study. The probability that providers of pastoral care have an expertise in hospice or palliative care increases if they are not merely involved in the practical work but also hold an administrative office within the hospice homecare service (e.g., as a member of the board of directors). There are pastors and other providers of pastoral care whose involvement in hospice work does not go beyond patient-oriented cooperation and for whom end-of-life pastoral care only represents a minor part of their work in pastoral care. The free-text responses to the survey indicate as much: "We regularly observe that community pastors [from] both of the large Christian denominations are overwhelmed in this area [i.e., hospice/palliative care]."

Several publications have discussed the importance of pastoral care at the end of life (Charbonnier, 2008; Buser et al., 2008; Lloyd-Williams et al., 2006). They conclude that pastoral care is not sufficiently integrated into palliative care and that pastoral care professionals require training in palliative care. Apart from formal facilitation of cooperation, it remains a challenge to equip (church-based) providers of pastoral care to accompany persons with a different religious or denominational background and (ethical) convictions (Charbonnier, 2008; Farley, 2014). Considering that healthcare professionals in German-speaking countries regard providers of pastoral care as the most important sources of spiritual care (Paal et al., 2014), cooperation between pastoral and hospice care deserves particular attention. The necessary clarifications must include clear distinctions between spiritual care (provided by hospice 
volunteers) and pastoral care (provided by chaplains, community pastors, or any other professional).

\section{LIMITATIONS}

Given the generally lower response rate of online surveys, our relatively low return rate of $25.0 \%(n=332)$ is still acceptable (Nulty, 2008). Nevertheless, multiple analyses do not seem warranted. The response rate is unusually low and makes multiple analysis unwarranted. However, the response rate can be attributed to the fact that the survey included both hospice homecare services with full-time professionals and hospice groups led by volunteers (who have limited human resources). Moreover, the timeframe for the survey partly overlapped with a popular vacation period.

Because of its character as a data collection and analytical study, our survey is limited in its reflection of actual needs and can therefore only affect the development of a curriculum to a limited extent. The survey did not include discussions about the most important contents for a potential training program. This is an issue that was addressed by a focus-group discussion conducted subsequently, which sought to define topics of high relevance for a future curriculum.

\section{CONCLUSIONS}

Given the assumption that spirituality is an essential part of a holistic understanding of hospice work and palliative care, the integration of spirituality and spiritual care into a concept for training volunteers remains a challenging task. It requires a shared and accepted basis that elucidates the meaning of the term "spirituality" for the purposes of training. However, a relevant understanding of spirituality itself is accessible only through encounters with patients and family members. This approach firmly rejects intentions to impose external standards of spirituality on recipients of hospice care. It also suggests a form of spiritual care that achieves expert management of the aspects of presence, listening, perception, acceptance, respect, and reaction. In order to successfully realize such a form of care, volunteers require access to a solidified personal standpoint. They must be involved in debating the possibilities and limitations of providing care, and they need to have experience interacting with patients.

\section{ACKNOWLEDGMENTS}

The authors would like to acknowledge the Bavarian Ministry of Labour and Social Affairs for its financial support.

\section{REFERENCES}

Alcorn, S.R., Balboni, M.J., Prigerson, H.G., et al. (2010). "If God wanted me yesterday, I wouldn't be here today": Religious and spiritual themes in patients' experiences of advanced cancer. Journal of Palliative Medicine, 13(5), 581-588.

Bericht des Bundesministeriums für Gesundheit (BMG) (2012). Zur Situation in der ambulanten und stationären Hospizversorgung für die 63: Sitzung des Ausschusses für Gesundheit des Deutschen Bundestages. Available from https://fachinformationen.diakonie-wissen.de/node/3513.

Borneman, T., Ferrell, B. \& Puchalski, C.M. (2010). Evaluation of the FICA tool for spiritual assessment. Journal of Pain and Symptom Management, 40(2), 163-173.

Brown, M.V. (2011). How they cope: A qualitative study of the coping skills of hospice volunteers. The American Journal of Hospice \& Palliative Care, 28(6), 398-402.

Büssing, A., Michalsen, A., Balzat, H.-J., et al. (2009). Are spirituality and religiosity resources for patients with chronic pain conditions? Pain Medicine, 10(2), 327-339.

Buser, K., Amelung, V.E. \& Schneider, N. (2008). German community pastors' contact with palliative care patients and collaboration with health care professionals. Journal of Social Work in End-of-Life \& Palliative Care, $4(2), 85-100$.

Charbonnier, R. (2008). Seelsorge in der Palliativversorgung. Wege zum Menschen, 60(6), 512-528.

Cooper, D., Aherne, M. \& Pereira, J. (2010). The competencies required by professional hospice palliative care spiritual care providers. Journal of Palliative Medicine, 13(7), 869-875.

DGP (Deutsche Gesellschaft für Palliativmedizin) (2007). Spirituelle Begleitung in der Palliativversorgung: Konzept des Arbeitskreises Spirituelle Begleitung der Deutschen Gesellschaft für Palliativmedizin. Available from http://www.dgpalliativmedizin.de/images/stories/pdf/ fachkompetenz/070709\%20Spirituelle\%20Begl\%20in\% 20Pm\%20070510.pdf.

Epstein-Peterson, Z.D., Sullivan, A.J., Enzinger, A.C., et al. (2014). Examining forms of spiritual care provided in the advanced cancer setting. The American Journal of Hospice \& Palliative Care, 32(7), 750-757. Epub ahead of print July 8.

Farley, V. (2014). The chaplain's role: Where aid in dying is legal. Health Progress, 95(1), 11-13.

Frick, E., Riedner, C., Fegg, M., et al. (2005). A clinical interview assessing cancer patients' spiritual needs and preferences. European Journal of Cancer Care, 15, $238-243$.

Gamondi, C., Larkin, P. \& Payne, S. (2013). Core competencies in palliative care: An EAPC white paper on palliative care education, part 2. European Journal of Palliative Care, 20(3), 140-145.

Gordon, T. \& Mitchell, D. (2004). A competency model for the assessment and delivery of spiritual care. Palliative Medicine, 18, 646-651.

Hagen, T. \& Raischl, J. (2011). Allgemeine und spezielle Kompetenzen in Spiritual Care. In Spiritualität und Medizin: Gemeinsame Sorge für den kranken Menschen, 2nd ed. E. Frick \& T. Roser (eds.), pp. 285-292. Stuttgart: Kohlhammer.

Hampton, D.M., Hollis, D.E., Dudley, A.L., et al. (2007). Spiritual needs of persons with advanced cancer. The American Journal of Hospice \& Palliative Care, 24(1), 42-48. 
Hanson, L.C., Dobbs, D., Usher, B.M., et al. (2008). Providers and types of spiritual care during serious illness. Journal of Palliative Medicine, 11(6), 907-914.

Hermann, C.P. (2007). The degree to which spiritual needs of patients near the end of life are met. Oncology Nursing Forum, 24(1), 70-78.

Höver, G.\& Schaeffer, A. (2009). Spiritualität und Menschenwürde in der Begleitung am Lebensende. Die Hospiz-Zeitschrift, 42(4), 4-8.

Lavenburg, P. \& Bernt, F. M. (2012). Training and supporting hospice volunteers: A regional survey. The American Journal of Hospice \& Palliative Care, 29(5), 355-361.

Lillis, B.S. (2014). Understanding the complex role of a hospice spiritual counselor. The American Journal of Hospice \& Palliative Care, 31(4), 353-355.

Liu, Y.J. (2014). A proposal for a spiritual care assessment toolkit for religious volunteers and volunteer service users. Journal of Religion and Health, 53(5), 1414-1426.

Lloyd-Williams, M., Cobb, M., Shiels, C., et al. (2006). How well trained are clergy in care of the dying patient and bereavement support? Journal of Pain and Symptom Management, 32(1), 44-51.

Marr, L.M., Billings, J.A. \& Weissman, D.E. (2007). Spirituality training for palliative care fellows. Journal of Palliative Medicine, 10(1), 169-177.

McSherry, W. \& Jamieson, S. (2011). An online survey of nurses' perceptions of spirituality and spiritual care. Journal of Clinical Nursing, 20, 1757-1767.

Meredith, P., Murray, J., Wilson, T., et al. (2012). Can spirituality be taught to health care professionals? Journal of Religion and Health, 51, 879-889.

Müller, M. \& Heinemann, W. (2014). Ehrenamtliche Sterbebegleitung: Handbuch mit Übungsmodulen für Ausbildende. Göttingen: Vadenhoeck \& Ruprecht.

Nolan, S., Saltmarsh, P. \& Leget, C. (2011). Spiritual care in palliative care: Working towards an EAPC task force. European Journal of Palliative Care, 18(2), 86-89.

Nulty, D.D. (2008). The adequacy of response rates to online and paper surveys: What can be done? Assessment \& Evaluation in Higher Education, 33(3), 308-314.

Okon, T.R. (2005). Palliative care review: Spiritual, religious, and existential aspects of palliative care. Journal of Palliative Medicine, 8(2), 392-414.

Owen-Still, S. (1985). Spiritual caregiving: A philosophy for the volunteer-intensive hospice program. The American Journal of Hospice Care, 2(2), 32-35.

Paal, P., Roser, T. \& Frick, E. (2014). Developments in spiritual care education in German-speaking countries. BMC Medical Education, 5(14), 112-118.

Paal, P., Helo, Y. \& Frick, E. (2015). Spiritual care training provided to healthcare professionals: A systematic review. The Journal of Pastoral Care \& Counseling, 69(1), 19-30.

Penderell, A. \& Brazil, K. (2010). The spirit of palliative practice: A qualitative inquiry into the spiritual journey of palliative care physicians. Palliative \& Supportive Care, 9, 415-420.

Pesut, B. (2003). Developing spirituality in the curriculum: Worldviews, intrapersonal connectedness, interpersonal connectedness. Nursing Education Perspectives, 24(6), 290-294.

Phelps, A.C., Lauderdale, K.E., Alcorn, S., et al. (2012). Addressing spirituality within the care of patients at the end of life: Perspectives of patients with advanced cancer, oncologists, and oncology nurses. Journal of Clinical Oncology, 30(20), 2538-2544.

Planalp, S., Trost, M.R. \& Berry, P.H. (2011). Spiritual feasts: Meaningful conversations between hospice volunteers and patients. The American Journal of Hospice \& Palliative Care, 28(7), 483-486.

Puchalski, C., Ferrell, B., Virani, R., et al. (2009). Improving the quality of spiritual care as a dimension of palliative care: The report of the consensus conference. Journal of Palliative Medicine, 12(10), 885-904.

Raab, M. (2005). Training spiritual care volunteers. An Indiana program teaches participants how to help people caught in crisis. Health Progress, Nov.-Dec., 60-61. Available from https://www.chausa.org/publications/ health-progress/article/november-december-2005/ training-spiritual-care-volunteers.

Radbruch, L. \& Payne, S. (2010). White paper on standards and norms for hospice and palliative care in Europe, part 2. Recommendations from the European Association for Palliative Care. European Journal of Palliative Care, 17(1), 22-33.

Roser, T. (2011). Innovation spiritual care: Eine praktischtheologische Perspektive. In Spiritualität und Medizin: Gemeinsame Sorge für den kranken Menschen, 2nd ed. E. Frick \& T. Roser (eds.), pp. 45-56. Stuttgart: Kohlhammer.

Roser, T. (2012). Spiritualität und Gesundheit: Überlegungen zur Bedeutung eines unbestimmbaren Begriffs im interdisziplinären Diskurs. In Spiritualität im Diskurs: Spiritualitätsforschung in theologischer Perspektive. R. Kunz \& C. Kohli Reichenbach (eds.), pp. 227-240. Zürich: Theologischer Verlag Zürich.

Scherwitz, L., Pullman, M., McHenry, P., et al. (2006). A contemplative care approach to training and supporting hospice volunteers: A prospective study of spiritual practice, well-being, and fear of death. Explore, 2(4), 304-313.

Surbone, A. \& Baider, L. (2010). The spiritual dimension of cancer care. Critical Reviews in Oncology/Hematology, $73,228-235$

Tan, H.M., Grief, M., Couns, P.C., et al. (2005). The impact of the hospice environment on patient spiritual expression. Oncology Nursing Forum, 32(5), 1049-1055.

Vallurupalli, M., Lauderdale, K., Balboni, M.J., et al. (2012). The role of spirituality and religious coping in the quality of life of patients with advanced cancer receiving palliative radiation therapies. The Journal of Supportive Oncology, 10(2), 81-87.

Wasner, M., Longaker, C., Fegg, M., et al. (2005). Effects of spiritual care training for palliative care professionals. Palliative Medicine, 19, 99-104.

Wesley, C., Tunney, K. \& Duncan, E. (2004). Educational needs of hospice social workers: Spiritual assessment and interventions with diverse populations. The American Journal of Hospice \& Palliative Care, 21(1), 40-46.

Wilson, P.E. (2000). Hospice volunteer training: Making the experience more meaningful. The American Journal of Hospice \& Palliative Care, 17(2), 107-110.

Yardley, S.J., Walshe, C.E. \& Parr, A. (2009). Improving training in spiritual care: A qualitative study exploring patient perceptions of professional educational requirements. Palliative Medicine, 23, 601-607. 